\title{
Taking advantage of early diagnosis: Preschool children with the 22q11.2 deletion
}

Marsha Gerdes, PhD ${ }^{1}$, Cynthia Solot, $M A^{2}$, Paul P. Wang, MD ${ }^{3,4}$, Donna M. McDonald-McGinn, MS ${ }^{4,5}$, and Elaine H. Zackai, $M D^{4-6}$

\begin{abstract}
Purpose: The purpose of this study is to review the neurodevelopmental outcome of infants and preschoolers with a 22q11.2 microdeletion and to discuss the our clinical observations of clinical implications for educational and therapeutic interventions. Methods: One hundred twelve children (4 to 70 mos) with the 22q11.2 deletion were assessed using standardized tests (Bayley Scales of Infant Development-II, Preschool Language Scales, Wechsler Preschool and Primary Scales of Intelligence-Revised). Results: Fifty-four percent of the children were significantly delayed, $24 \%$ had mild delay, $22 \%$ had average cognitive development, and $80 \%$ were below average in language development. Delays are not explained by cardiac defects or palatal defects. Conclusion: Developmental delays, mild hypotonia, language and speech delays, and feeding disorders are common, and this finding indicates the need for early intervention services beginning in infancy for children with the $22 q 11.2$ deletion. Genetics in Medicine, 2001:3(1):40-44.
\end{abstract}

Key Words: DiGeorge syndrome, velocardiofacial syndrome, neurodevelopmental outcome, early intervention

The chromosome 22q11.2 deletion has an incidence of approximately 1 in 4,000. DiGeorge syndrome, ${ }^{1,2}$ velocardiofacial syndrome (VCFS), ${ }^{3}$ and conotruncal anomaly face syndromes, ${ }^{4}$ and some patients with autosomal dominant Opitz G/BBB syndrome, ${ }^{5,6}$ isolated conotruncal cardiac anomalies, ${ }^{7}$ and Cayler cardiofacial syndrome ${ }^{8}$ have been associated with the 22q11.2 deletion. The pattern of physical findings associated with the $22 \mathrm{q} 11.2$ deletion varies from patient to patient ${ }^{9}$ and includes a conotruncal cardiac defect, palatal anomalies such as an overt cleft palate or velopharyngeal incompetence, thymic aplasia, or hypoplasia, T-cell abnormalities, and minor facial anomalies. These signs are now widely recognized. Many cardiologists are now routinely screening for the 22q11.2 deletion by the use of the FISH in all children with conotruncal cardiac anomalies at birth. Thus, parents are receiving news of the diagnosis often in the first days and weeks following the birth of their child. Early diagnosis can function as an advantage to the family, allowing them to screen for deficits and to initiate early intervention strategies. Parents of newborns will be particularly interested in recommendations for intervention. The aim of this paper is to review and update the developmental findings associated specifically with the 22q11.2 deletion, including cognitive, speech and language, and

\footnotetext{
From the ${ }^{1}$ Department of Pediatric Psychology, ${ }^{2}$ Communicative Disorders, and ${ }^{3}$ Division of Child Development and Rehabilitation, Children's Seashore House of the Children's Hospital of Philadelphia, Philadelphia, Pennsylvania; ${ }^{4}$ Departments of Pediatrics, ${ }^{5}$ Human Genetics and Molecular Biology, ${ }^{6}$ Department of Obstetrics and Gynecology, The Hospital of the University of Pennsylvania, Philadelphia, Pennsylvania.

Dr. Marsha Gerdes; The Children's Hospital of Philadelphia, 34th and Civic Center Boulevard, Philadelphia, PA 19104-4399.

Received: August 14, 2000

Accepted: November 6, 2000
}

neuromuscular development and behavioral characteristics in a preschool population; and to report on our clinical experience of the clinical implications of the findings, specifically educational and therapeutic intervention strategies.

\section{MATERIALS AND METHODS}

\section{Study population}

A total of 112 preschool children with a 22q11.2 deletion under the age of 6 years were identified by the Clinical Genetic Services of The Children's Hospital of Philadelphia [CHOP]. Children were referred to the CHOP Clinical Genetic Center for evaluation from the departments of Cardiology, Plastic Surgery, Immunology and Child Development. No patients refused to participate in these aspects of the study. In all instances, they were participants in the established center for children with a 22q11.2 deletion. Diagnosis of the 22q11.2 deletion was accomplished using fluorescence in situ hybridization (FISH) analysis of metaphase spreads prepared from peripheral blood lymphocyte cultures using the N25 probe (Oncor), which maps to the DiGeorge chromosomal region (DGCR).

Subjects ranged in age from 4 months to 6 years. Of the 112 patients, 50 were females. Twenty-two were evaluated in infancy before 12 months of age, 55 between 13 months and 42 months of age, and 35 between 42 months and 6 years of age.

\section{Physical and neurological evaluation}

A team including a pediatric psychologist (MG), developmental pediatrician (PW), and speech-language pathologist (CS) saw each child. 


\section{Developmental assessment}

Cognitive

Children who were 4 to 42 months old were assessed by a licensed pediatric psychologist using the Bayley Scales of Infant Development - 2nd Edition (BSID). ${ }^{10}$ This test yields two scores: Mental Developmental Index (MDI) and Psychomotor Development Index (PDI). Each has a mean of 100 and a standard deviation of 15. Mental scale includes assessment of cognition, language, fine motor and social abilities. The motor scales include assessment of fine and gross motor abilities. $\mathrm{Pa}$ tients were grouped into three levels of functional status according to the following criteria: Average if the MDI was within one standard deviation of the mean, Mildly Delayed if the MDI was between one and two standard deviations below the mean, and Significantly Delayed if the MDI was more than 2 standard deviations below the mean. Children above the age of 4 years were assessed using the Wechsler Preschool and Primary Scales of Intelligence-Revised (WPPSI-R). The WPPSI-R yields three scores: Full Scale IQ, Performance IQ and Verbal IQ. Each has a mean of 100 and a standard deviation of 15

\section{Language}

Language was assessed in an individual evaluation by a certified, licensed speech-language pathologist. The Preschool Language Scales-3 (PLS-3) was used. ${ }^{11}$ This is a standardized assessment, which includes two subscales - Auditory Comprehension and Expressive Communication. The test yields three scores, receptive, expressive, and total language scores, each with a mean of 100 and a standard deviation of 15 .

\section{Behavior}

Spontaneous behavior noted during the developmental assessment was documented in a clinical observation form, and parents were interviewed.

\section{Statistical method}

Statistical analyses were performed using Microsoft Excel 97.

\section{RESULTS}

\section{Development in infancy}

Twenty-two infants were seen at $<12$ months of age. The mean age was 8.5 months with a range of 4 months to 12 months. The mean MDI was $76 \pm 14$, which is in the Mildly Delayed range, and the mean PDI was $65 \pm 13$, which is in the Significantly Delayed range. Within this age group, $27 \%$ of the infant were functioning with normal limits, $32 \%$ were mildly delayed and $41 \%$ were significantly delayed. Those children demonstrating delays typically demonstrated global delays in their development with cognitive skills, motor skills, and speech and language skills all being delayed. Early gross motor milestones were delayed with independent sitting and crawling being late in developing. This was probably related to hypotonia. Often, prone skills were poor, and infants actively pro- tested when placed in a prone position. This finding seems secondary to low upper extremity muscle tone. Toy play emerges in a typical pattern of development but at a slower than average rate. In infancy, children spend longer time in manipulative (shaking and banging) play with functional purposeful play emerging after 12 months. Prespeech milestones such as babbling and gesturing were also delayed.

\section{Development in toddlers}

Assessments of mental development in the toddler group $(\mathrm{N}=55)$ showed 32 children $(58 \%)$ functioning in the Significantly Delayed performance range, 11 children (20\%) were functioning in the Mildly Delayed performance range, and 11 children $(22 \%)$ were functioning in the Average range. The mean MDI is $67 \pm 15$, which falls in the significantly delayed range, and the mean PDI was $61 \pm 13$. The diagnosis of mental retardation was not applied due to the young age of the children. When a child scored in the significantly delayed range on the Bayley Scales of Infant Development, typically there was evidence of delays in all areas of learning-cognition, motor, self-help, as well as language. Speech and language delays were present in all children assessed. Fine motor delays and delays in the acquisition of gross motor skills of crawling and walking independently were found in children with normal and abnormal neuromuscular tone. Average age of walking was 18 months.

\section{Development in preschoolers}

Of the 35 children over $3 \frac{1}{2}$ years of age, 24 were assessed using the WPPSI-R and 11 were assessed using the Bayley Scales of Infant Development because of lower functioning skills. In those children who were assessed using the BSID, a developmental quotient ( $\mathrm{DQ}=$ mental age derived from performance on mental scale/chronological age mean 100) was derived. In the whole group of 35, 12 children (34\%) were diagnosed with mild mental retardation, 11 children $(32 \%)$ were functioning in the borderline range of intelligence, and 12 children (34\%) were functioning in the average range of development. Of those who were assessed using the WPPSI-R, the mean Full Scale IQ was $78 \pm 12$, mean VIQ was $78 \pm 12$, and mean VIQ was $81 \pm 13$. Forty-four percent of the children had a difference of $>9$ points between Performance IQ and Verbal IQ at a statistically significant level. Four cases revealed higher verbal subtest scores, and one case had higher performance subtest scores.

\section{Speech and language development: infants to preschoolers}

Emergence of language skills was delayed in most children. Of the 50 children assessed by the speech pathologist, the mean and SD of the total language score was $76 \pm 11 ; 17(34 \%)$ patients scored 2 SD below mean (range 50-69), $23(46 \%)$ patients were 1 SD below mean (range 71-83), and $10(20 \%)$ children were in the average range (range 91-108). The mean and SD for the expressive language score and the receptive score were $75 \pm 12$ and $82 \pm 11$, respectively. 


\section{Behavior}

Five children were diagnosed with a psychiatric disorder in the preschool years. Three children were diagnosed here with Pervasive Developmental Disorder, NOS. One child was diagnosed in his community with bipolar disorder at the age of 4 years and 9 months. Another child who also has mild mental retardation was diagnosed here with Disruptive Behavior Disorder. An additional child was reported to have multiple characteristics of the PDD but did not meet the entire criterion for the diagnosis.

In other children who did not meet criteria for psychiatric diagnosis, a pattern of behavior was observed which has the following characteristics: Self-directed behavior, noncompliance, high activity, and poor social skills. Children demonstrating this pattern of behavior typically prefer independent play and do not naturally adopt a pattern of doing things to please an audience or receive praise. Typically, the child with a 22q11.2 deletion will always return a smile with a smile and interact socially but typically do not seem motivated by praise or work for attention or applause from the parent to the same extent as other children. Often parents report that there is a reluctant willingness to follow adult directions. This behavior expresses itself differently at different ages. It is generally not defiant behavior, rather it is more the absence of a pattern of compliance. Impulsive behavior and high activity level is noted in some but not all. Social skills are often delayed. Children with 22q11.2 are often limited in the variety of facial expressions that they use or are limited in the frequency with which they change their expressions, so that when they play, they often look serious. Their self-directed play style does not promote peer interactions or cooperative play, and language delays inhibit some interactions.

Table 1 presents a summary of these findings.

\section{DISCUSSION}

This study is a follow-up to the first prospective multidisciplinary evaluation to focus solely on toddlers and preschool age children diagnosed with a 22q11.2 deletion. ${ }^{12}$ It reports now on 112 preschool children which triples the study population of the previous reports. The consistency of these findings with the earlier accounts by Gerdes et al., ${ }^{12}$ Shprintzen et

Table 1

Developmental outcome of 112 preschoolers with 22q11.2 deletion

\begin{tabular}{lccc}
\hline & $\begin{array}{c}\text { Average } \\
(>85)\end{array}$ & $\begin{array}{c}\text { Mildly delayed } \\
(70-84)\end{array}$ & $\begin{array}{c}\text { Significantly } \\
\text { delayed } \\
(<70)\end{array}$ \\
\hline Mental development (\%) & 23 & 24 & 52 \\
Motor development (\%) & 10 & 36 & 54 \\
Full IQ (\%) & 34 & 32 & 33 \\
Total language (\%) & 20 & 46 & 34 \\
\hline
\end{tabular}

Based on the Mental Developmental Index scores of the Bayley Scales of Infant Development and Preschool Language Scale. al., ${ }^{13,14}$ Swillen et al., ${ }^{15}$ and Goldberg et al. ${ }^{16}$ affirms that the early descriptions of this population were accurate. There is a wide range of expression of developmental and behavioral findings. In the preschool years children with a 22q11.2 deletion are most commonly found to be developmentally delayed, hypotonia and language and speech delays. The more significantly delayed children are at high risk to be subsequently diagnosed with mild or moderate mental retardation. Severe and profound retardation was not seen. A few patients are functioning within the average range; however, even those with age-appropriate skills obtained developmental scores in the low average range. Hypotonia has been documented in $50 \%$ of infants in previous studies. ${ }^{12}$

In order to determine factors contributing to the developmental course in young children, we previously looked at the role of cardiac defects and surgery, cleft palate, and hypotonia. Surprisingly, delays in development were independent of any of these factors. Children with cardiac defects, cleft palate defects, or hypotonia were no more likely to have developmental delay than those without the defects. The variation of development was not explained by other medical conditions of the child. The data suggest that the global delays and variations in intelligence are directly associated with the 22q11.2 deletion and are not explained by physical anomalies such as palatal defects or cardiac defects or therapeutic interventions such as cardiac surgery.

A history of mild and significant delays in language was present in all of the children. Language delays as evidenced by scores on standardized language scales of below average were present in $40 \%$ of the children. Previous studies found that two-thirds of the population do not have any verbal communication skills by 2 years of age. Delays in expressive language were beyond that expected for their developmental level. Voice quality disturbances, low facial tone, articulation errors, dysarthria were present in many preschoolers. ${ }^{17}$ These findings highlight the need for early evaluation and therapy designed to develop communication strategies best suited to the child's needs. In nonspeaking children, we feel that the use of alternative communication strategies such as manual signs can reduce frustration, increase communicative competencies and serve as a bridge toward the development of more conventional speech/language symbols.

Although some reports of the school-aged population of children with 22q11.2 emphasize a nonverbal learning disability (NVLD), ${ }^{18}$ it is important to recognized that the presence of NVLD does not preclude language deficits. In fact, the deficits in language reported here are also reported in the school-age population. ${ }^{17}$

Feeding disorders are known to be a major difficulty for children with a 22q11.2 deletion in the first 3 years of life. ${ }^{19}$ The incidence of feeding disorders has been reported as present in $67 \%$ in preschoolers with 22q11.2. ${ }^{12}$ Some problems noted included decreased volume intake, immature or inadequate tongue movement, nasopharyngeal reflux, food selectivity, delayed transition to higher textured foods, choking, esophageal and pharyngeal movement problems. Reflux can also be 
present in those with feeding disorders. Previous reports found that feeding disorders were present in children regardless of the presence of cardiac or palatal anomalies and were not associated with global delays. ${ }^{12}$

There does not appear to be a single distinct behavioral expression of the 22q11.2 deletion in the preschool period. Five of the 112 were diagnosed with a psychiatric disorder (3 PDD, 1 bipolar, and 1disrputive). Others demonstrated a pattern of noncompliance and self-directed behavior with poor social skills. As in previous studies of similar populations, ${ }^{20}$ there is a prevalence of behaviors including impulsiveness, disinhibition and attention disorders. There are some reports of shyness and poor social skills. The presence of poor facial tone plus the presence of expressive language delays may contribute to the finding of social withdrawal and shyness in some children. Given the later reports of more severe psychopathology in older patients with $22 \mathrm{q} 11.2$ deletion, ${ }^{13,16}$ it is important to monitor the behavioral and emotional health of these children.

Children with a 22q11.2 deletion can have a very complex developmental presentation, including cognitive delays, language delays, feeding disorder, motor delays, and behavior abnormalities. Each child should be individually assessed and an educational and therapeutic program should be developed.

\section{Clinical implications of developmental findings}

Within the United States, educational and therapy services are available to children starting at birth. Each state has developed a system for evaluation and for the provision of services. States determine criteria for eligibility and the method of service delivery. There is a wide variation among the states in service models and eligibility criteria. The most common criteria for services is $25 \%$ or $33 \%$ delays in one or more areas of development (cognitive, speech and language, fine motor, gross motor, sand social-emotional) or a neonatal diagnosis which places a child at risk for later developmental delays. Since most of the preschool children we studied were experiencing some degree of delay, the use of a preventive model is appropriate. The efficacy of early intervention in reducing the impact of a disability is well recognized..$^{21}$ We suggest that all children with 22q11.2 will be eligible for monitoring or additional services, because they are at high risk for developmental disabilities.

As young children enter the early intervention system, an individualized program is developed for each child. Below the age of 3, this is called an Individualized Family Service Plan (IFSP), and at 3, it is called an Individualized Educational Plan (IEP). Within these documents, the needs of the family and child are documented and a plan for meeting those needs is developed by the family and early intervention team working together. The best use of the IFSP and IEP is to be very thorough in the description of the child's strengths and weakness and to set multiple goals, short term and long term, in each area. If specific therapy techniques are needed, that should be included in the plan. Early intervention providers are an excellent source of information and therapy services. Although they might not be experienced with children with the deletion, they will have a valuable basis of knowledge in child development and therapy techniques. Parents can advocate for their child by providing their service providers with information about the deletion and by insisting on high quality services.

Each child with 22q11.2 deletion will be different and individual assessment by early intervention teams or a psychologist is recommended. Educational monitoring is recommended if there are not apparent delays or delays that are less serious than the state's criteria for provision of services.

If delays are present, an early children specialist, special instructor, or special education teacher is recommended on a weekly basis initially. It is important with all therapies and services that the families are involved, learning the activities and finding new ways to support and challenge their child. Once the child's interventions are center based, which often occurs at the age to 3, daily educational services are recommended. If available children do best when attending preschool in an integrated setting where typically developing children and those with special needs are together in the same classroom. If a child attends a typical preschool in their community, consultation to the classroom teacher and weekly or biweekly direct services are beneficial.

If delays in social skills or behavioral concerns are present, the IFSP or IEP should include goals related to social-emotional development. Goals might address increasing compliance and social interaction. Children will benefit from peer interactions. Structured social experiences are important. The question of inclusion, that is being in a classroom with age mates, should be considered individually, but most children benefit from being with typically developing peers. Special needs settings do, however, typically offer a most intensive schedule of therapies, which may at times be necessary.

If there are behavioral concerns, a behavior specialist should be consulted. An individualized behavioral program to carry out in the school or home is very helpful. This is a responsibility of the Birth to Five service provider.

Speech and language delays are present in almost all children with the 22q11.2 deletion. These findings are apparent in the first year of life. Interventions for these children should start early and involve the families. The use of total communication approach along with phoneme placement therapy is generally recommended. Solot has describes the type of speech deficits, and therapy is described in detail in the accompanying article. Total communication, which includes the use of American Sign Language, gestures, and verbal speech, is recommended for a number of reasons. The benefits of providing children without verbal speech with an alternative mode of communication are in lessening frustration, encouraging communication, allowing greater reciprocal social interaction, stimulating imitation skills, maintaining an interest in communication, and increasing receptive language skills.

The best approach to hypotonia is physical therapy. Physical therapy can begin in infancy to strengthen muscle tone and to assist children in acquiring gross motor milestones. In the first year of life, prone skills need to be encouraged. Often physical therapy is discontinued once a child is walking independently, 
despite the continuation of gross motor delays and the continued presence of hypotonia. Services should continue as long as the child demonstrates a delay. Children will benefit from physical therapy, and advances in muscle tone and coordination can have a positive impact on speech and feeding as well.

Concerns about feeding are primary in the preschool years, and feeding therapy can be beneficial. ${ }^{14}$ Feeding therapy styles vary from location to location, and in some places is difficult to find.

\section{SUMMARY}

Preschool children with 22q11.2 deletion demonstrate common findings of cognitive delays, language delays, feeding problems, and motor deficits; however, there is a range in the expression of the disabilities from very mild to more significant disabilities. Early counseling for parents should emphasize the need to view the child as an individual. Knowing that 22q11.2 deletion is the etiology of delays does suggest some specific interventions. First, early hypotonia is not benign, and physical therapy can be effective. Second, expressive language difficulties can be detected early and preventive speech therapy, including use of sign language, should be introduced by 1 year of age. Third, social skills training should also begin early. Other interventions such as special instruction or occupational therapy are not unique to the $22 \mathrm{q} 11$ population but are appropriate for all children with developmental delays.

\section{Acknowledgments}

These studies were supported by funds from the NIH (VCFS DC02027), SCOR (HL62177), and NICDC (MRRC HD26979). We thank the families of children with 22q11.2 who participated in this study for their dedication to their children and this project.

\section{References}

1. Scrambler PJ, Carey AH, Wyse RKH, Roach S, Dumanski JP, Nordenskjold M, Williamson R. Microdeletions within 22 associated with sporadic and familial DiGeorge syndrome. Genomics 1991;10:201-206.

2. Driscoll DA, Budarf ML, Emanuel BS. Mapping the critical region in DiGeorge syndrome. Am J Hum Genet 1991;49:18.

3. Driscoll DA, Spinner NB, Budarf ML, McDonald-McGinn DM, Zackai EH, Goldberg RB, Shprintzen RJ, Saal HM, Zonana J, Jones MC, Mascerello JT, Emanuel BS.
Deletions and microdeletions of 22q11.2 in velo-cardio-facial syndrome. Am J Med Gen 1992;44:261-268.

4. Burn J, Takao A, Wilson D, Cross I, Momma K, Wadey R, Scambler P, Goodship J. Conotruncal anomaly face syndrome is associated with a deletion within chromosome 22q11. J Med Genet 1993;30:822-824.

5. McDonald-McGinn DM, Driscoll DA, Bason L, Christensen K, Lynch D, Sullivan K, Canning D, Zavod W, Quinn N, Rome J, Paris Y, Weinberg P, Clark BJ, Emanuel BS, Zackai EH. Autosomal dominant "Opitz" GBBB syndrome due to a 22q11.2 deletion. Am J Med Genet 1995;59:103-113.

6. Fryburg JS, Lin KY, Golden WL. Chromosome 22q11.2 deletion in a boy with Opitz [G/BBB] Syndrome. Am J Med Genet 1996;62:274-275.

7. Goldmuntz E, Driscoll D, Budarf ML, Zackai EH, McDonald-McGinn D, Biegel JA, Emmanuel BS. Microdeletions of chromosomal region 22q11.2 in patients with congenital conotruncal cardiac defects. J Med Genet 1993;30:807-812.

8. Giannotti A, Diglio MC, Marion R, Mingarelli R, Dallapiccola B. Cayler cardiofacial syndrome and deletion 22q11: part of the CATCH22 phenotype. Am J Med Genet 1994;53:303-304.

9. McDonald-McGinn DM, LaRossa D, Goldmuntz E, Sullivan K, Eicher P, Gerdes M, Moss E, Wang, Solot C, Schultz P, Lynch D, Bingham P, Keenan G, Weinzimer S, Ming JE, Driscoll D, Clark III BJ, Markowitz R, Cohen A, Moshang T, Pasquariello P, Randall P, Emanuel BS, Zackai EH. The 22q11.2 deletion: screening, diagnostic workup, and outcome of results; report on 181 patients. Genet Test 1997;1:99-107.

10. Bayley N. Bayley scales of infant development-2nd Ed. San Antonio, TX: Psychological Corporation, 1993.

11. Zimmerman IL, Steiner VG, Pard, RE. Preschool language scales-3. San Antonio, TX: Psychological Corporation, 1991.

12. Gerdes M, Solot C, Wang P, Moss E, LaRossa D, Randall P, Goldmuntz E, Clark BJ, D Driscoll D, Jawad A, Emmanuel B, McDonald-McGinn D, Batshaw M, Zackai E. Cognitive and behavioral profile of preschool children with chromosome 22q11.2 deletion. Am J Med Genet 1999;85:127-133.

13. Shprintzen RJ, Goldberg R, Golding-Kushner KJ, Marion R. Late onset psychosis in the velo-cardiofacial syndrome. Am J Med Genet 1992;42:141-142.

14. Shprintzen RJ, Goldberg RB, Young D, Wolford L. The velo-cardio-facial syndrome: a clinical and genetic analysis. Pediatrics 1981;67:167-172.

15. Swillen A, Devriendt K, Legius E, Eyskens B, Dumoulin M, Gewillig M, Fryns JP. Intelligence and psychosocial adjustment in velocardiofacial syndrome: a study of 37 children and adolescents with VCFS. J Med Genet 1997;34:453-458.

16. Goldberg R, Motskin B, Marion R, Scambler PJ, Shprintzen RJ. Velo-cardio-facial syndrome: a review of 120 patients. Am J Med Genet 1993;45:313-319.

17. Solot C, Kinghtly C, Handelr S, McDonald-McGinn D, Gerdes M, Moss E, Wang P, Cohen M, Randall P, LaRossa D, Driscoll D, Emanuel B, Zackai, E. Communication disorders in the 22q11.2 Microdeletion Syndrome. J Commun Disord 2000;33:187204.

18. Moss EM, Batshaw ML, Solot CB, Gerdes M. McDonald-McGinn DM, Driscoll DA, Emmanuel BS, Zackai EH, Wang PP. Psychoeducational profile of the 22q11.2 microdeletion: a complex pattern. J Pediatr 1999;134:193-198.

19. Eicher PS. Feeding Issues: Old challenges, New solutions. Presentation at 22q11.2 deletion, ringing the 22q11.2 deletion into the 21 st Century. Second International Conference for Families and Professionals. June 2000, Philadelphia, Pa.

20. Golding-Kushner KJ, Weller G, Shprintzen J. Velo-cardio-facial syndrome: language and psychological profiles. J Craniofac Genet Dev Biol 1985;5:259-266.

21. Ramey C, Ramey SL. Early intervention and early experience. Am Psychol 1998;53: 109-120. 